\title{
A study to assess nutritional status, nutrition knowledge and dietary patterns of college going adolescent girls
}

Received: 26.03.2016; Revised: 14.05.2016; Accepted: 26.05.2016

Author for Correspondence :

\section{VIJAYETA PRIYADARSHINI}

Department of Home Science, Govt. Women's College, KEONJHAR (ODISHA) INDIA

Email : vijayeta.priyadarshini@ gmail.com
ABSTRACT : Knowledge about food is considered to be beneficial not only for food choice and healthy weight reduction but also as concerns its long-term implications for general health. Continuation of poor eating choices and unhealthy diet can lead to many health problems including obesity, malnutrition, cardiovascular diseases, diabetes etc. Healthy eating habits promote growth and reduce many risks associated with both immediate and long-term health problems. The main objectives of the present study were to assess nutrition related knowledge and dietary habits and practices of college going adolescent girls. The data was collected through survey method with the help of a structured questionnaire from 110 respondents. About 39 per cent of the respondents were underweight. Nutrition related knowledge of adolescent girls was not at all satisfactory.

KEY WORDS: Adolescent girls, Nutritional status, Nutrition knowledge, Food habits, Dietary patterns

- HOW TO CITE THIS PAPER : Priyadarshini, Vijayeta (2016). A study to assess nutritional status, nutrition knowledge and dietary patterns of college going adolescent girls. Asian J. Home Sci., 11 (1) : 232237, DOI: 10.15740/HAS/AJHS/11.1/232-237. 